\title{
What FinTech Can Learn from High-Frequency Trading: Economic Consequences, Open Issues and Future of Corporate Disclosure
}

\author{
Eleonora Monaco
}

\begin{abstract}
This chapter provides a review on key literature on HighFrequency Trading (HFT) over an 11 -year period. Using a thematic analysis, the main themes developed within this research stream are identified and insights on the evolution of theory in relation to HFT are presented. This analysis highlights that the effects of HFT on market liquidity, trading strategies and speed, implications for market structure changes, and the relationship between the "scriptability" of corporate disclosure and HFT short-term information advantage, are key themes.
\end{abstract}

\footnotetext{
E. Monaco $(\square)$

Católica Porto Business School, Universidade Católica Portuguesa, Porto, Portugal e-mail: emonaco@porto.ucp.pt

E. Monaco

European Capital Markets Cooperative Research Centre, Chieti, Italy

(C) The Author(s) 2019

T. Lynn et al. (eds.), Disrupting Finance, Palgrave Studies in Digital Business \& Enabling Technologies, https://doi.org/10.1007/978-3-030-02330-0_4
} 
The analysis also suggests that many open questions remain unanswered including more recent HFT trading strategies and complex techniques applied to analyse the content of both voluntary and mandatory corporate disclosure. As capital markets evolve, HFT's speed may no longer be sufficient to maintain competitiveness. The chapter concludes with a discussion of future trends and areas for research on HFT.

Keywords High-frequency trading - Literary review - Market quality • Regulation - Corporate disclosure scriptability

\subsection{INTRODUCTION}

In the last years, investment in financial technology (FinTech) grew by $201 \%$ around the world; total venture capital investments only grew by $63 \%$ in the same period (Aldridge and Krawciw 2017). According to Informilo.com, in 2015 payment services, online loans, data analytics and automated investing have resulted in the fastest-growing areas for big data in finance. Specifically, investment automation and other new related technologies have transformed the structure of capital markets. Reducing market-wide latency, the introduction of both co-location services and fast trading platforms enable new sophisticated investors to enter into the market. Therefore, using high speed and high-performance computing, sophisticated tools and algorithms, algorithmic traders (AT) rapidly trade securities in the main stock exchanges around the world. These changes and the behaviour of market participants attract considerable attention by both the academic community and policymakers. Many papers discuss the role played by AT in capital markets as well as their trading strategies and consequences for market quality. Similarly, market regulators have expressed concerns about the growing participation of ATs and the costs associated with monitoring their activities.

This chapter provides a review of the High-frequency trading (HFT) literature based on 11 years of publications, discusses HFT consequences on capital markets, and suggests future research directions. Following a similar approach adopted by prior studies (Massaro et al. 2016), this chapter aims to answer three questions:

- What are the major themes that have been discussed in HFT research field? 
- What are the main issues and critique on HFT activity?

- What is the future of HFT research?

The remainder of this chapter is organised as follows. The next section considers the differing approaches to defining HFT by both regulators and scholars and presents an overview of common datasets used to investigate HFT activity. This is followed by a summary of the methodology used for the literature review and associated data collection. The results of the literature review are then presented. The chapter concludes with a discussion of the findings and directions for future research.

\subsection{High-Frequency Trading: Definition and Data}

In general, total trading activity can be classified into two main categories: algorithmic trading (AT) and non-algorithmic trading activity (NAT) depending on whether or not market participants use algorithms to make trading decisions without human intervention (ESMA 2014). The European Markets in Financial Instruments Directive (MiFID II) provides two different definitions of the concepts HFT and AT, where the former is a subset of the latter. Specifically, AT is defined as "[...] trading in financial instruments where a computer algorithm automatically determines individual parameters of orders, such as whether to initiate of an order or how to manage the order after its submission, with limited or no human interaction" (MiFID II 2014, p. 384). This does not include any system that is only used for the purpose of routing orders to one or more trading venues or for the processing of orders involving no determination of any trading parameters or for the confirmation of orders or the post-trade processing of executed transactions (MiFID II 2014). Moreover, the MiFID II (2014, pp. 384-385) defines HFT as "an algorithmic trading technique that is characterized by an infrastructure that minimize network and other type of latencies using specific facilities as co-location, proximity hosting or high-speed direct electronic access and by a system determination of order initiation, generation and execution without human intervention for trades or orders".

The U.S. Securities and Exchange Commission takes a broader approach in defining HFT as "professional traders acting in a proprietary capacity that engage in strategies that generate a large number of trades on a daily basis" (SEC 2010, p. 45). Similarly, the Australian Securities and Investments Commission emphasises HFT's ability to generate large 
numbers of orders, many of which are cancelled rapidly and to hold positions for very short time horizons (ASIC 2010).

Although there is no common definition of HFT, several regulatory agencies and scholars do attempt to identify two main features and trading strategies of HFT, namely: (i) the automation of the trading process, and (ii) the high speed of transactions and submission (cancellation) of orders.

Different methods have been applied to classify HFT activities. For example, the definition used by SEC (2010) allows the identification of HFT activities but fails to detect large blocks of HFT. Some scholars instead detect such blocks by focusing on the evidence of high trading volume and balance inventory (Kirilenko et al. 2017) or on complex trading strategies characterised by "series of submissions, cancellations, and executions that are linked by direction, size and timing, and which are likely to arise from a single algorithm" (Hasbrouck and Saar 2013, p. 656).

Given that only a few datasets (such as E-Mini Data and NASDAQ data) allow the identification of HFT, most studies are based on proxies to detect HFT activity and highlight the effects of HFT on capital markets. The current HFT datasets available can be classified into five categories:

- Data for equity trading on NASDAQ;

- Data on trading in the E-Mini;

- Data that CFTC and SEC staff used to prepare their report on the market disruption that occurred in 2010 (Flash Crash);

- A variety of datasets made available to researchers by exchanges and regulators that require proxies to identify HFT activity.

According to Boehmer et al. (2018) and Hendershott et al. (2011), message traffic can include new order submissions, modifications or order cancellations. Hence, the main proxies used by researchers are trading volume (Clark-Joseph 2013; Baron et al. 2017; Kirilenko et al. 2017), raw messages, the ratio of both trading volume and number of messages (Hendershott et al. 2011), and the ratio of messages and total transactions.

\subsubsection{Methodology}

This section explains the methods for selecting and reviewing the articles examined in this study. Following the methodology used in Massaro et al. (2016) and similar approaches used by prior studies, a dataset of articles was constructed. The dataset counts HFT articles published in 
the main accounting and finance journals featured in the Scopus database by Elsevier for the 11-year period from 1 January 2007 to 15 May 2018. In order to be included in the sample, articles must mention the terms "high-frequency trading" or "algorithmic trading" in the title, abstract or keywords. Those papers that did not meet the required conditions were discarded, reducing the list of articles to 265 articles (either published or forthcoming on 15 May 2018). Author details, article title, year of publication, SCOPUS citations, affiliation of authors and location were collected.

Firstly, the articles were classified based on whether they were published in generalist or specialist journals. 87 articles were published in general journals, while 178 articles were published in specialist journals. The latter category includes journals whose scope focuses specifically on HFT activity e.g. Algorithmic Finance Journal, on trading issues and structures of financial markets e.g. Journal of Finance, Journal of Financial Economics, Journal of Financial Markets, Journal of Empirical Finance and others.

Secondly, the selected articles were classified by examining their citations to measure the academic impact of each article and to provide insights into the evolution of the literature (Table 8.1). The journals were further categorised by ABS Journal Ranking (or not) and the main topics covered in each article were identified.

\subsubsection{Descriptive Statistics}

This section reports some descriptive statistics to provide a clear picture of the evolution of the HFT literature. The first article that refers to the "activity of algorithmic trading" was published in 2007 (Prix et al. 2007) and describes the systematic patterns in the submission and cancellation of certain Xetra orders. ${ }^{1}$ Figure 4.1 shows the evolution of the volume of papers published in generalist or in specialist journals ranked by Scopus in the chose time period. A sharp increase in the articles is evident from 2010 , following the "Flash Crash" in May of that year, which signalled the start of increased academic discussion of the consequences of HFT activity on capital markets.

However, the largest number of contributions was published in the four years between 2013 and 2017 in which not only specialist journals but also generalist journals published articles (123 and 58 articles,

\footnotetext{
${ }^{1}$ The advantage of "the predatory traders" over uninformed traders has been discussed for the first time by Brunnermeier and Pedersen (2005).
} 


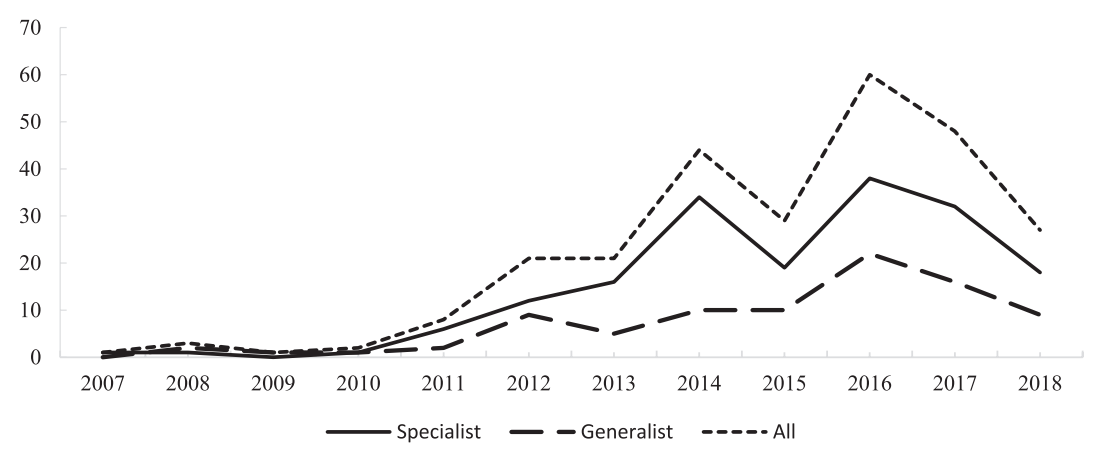

Fig. 4.1 Volume of articles on HFT ranked by Scopus in the period 2007-2018

respectively) noting the consequences of HFT activity on capital markets as well as the impact of new regulation, released by different countries, to limit their presence.

An examination of author affiliation allows the identification of the institutions in which researchers conducted their studies on HFT. This analysis suggests that the leading institutions publishing in the field of AT research include The University of Toronto, The University of California Berkeley, The University of Oxford, The University of Sydney, The University of Washington and Imperial College London. The majority of studies were developed in USA (30\%), UK (14\%), France (7\%) and Australia (7\%) (Fig. 4.2).

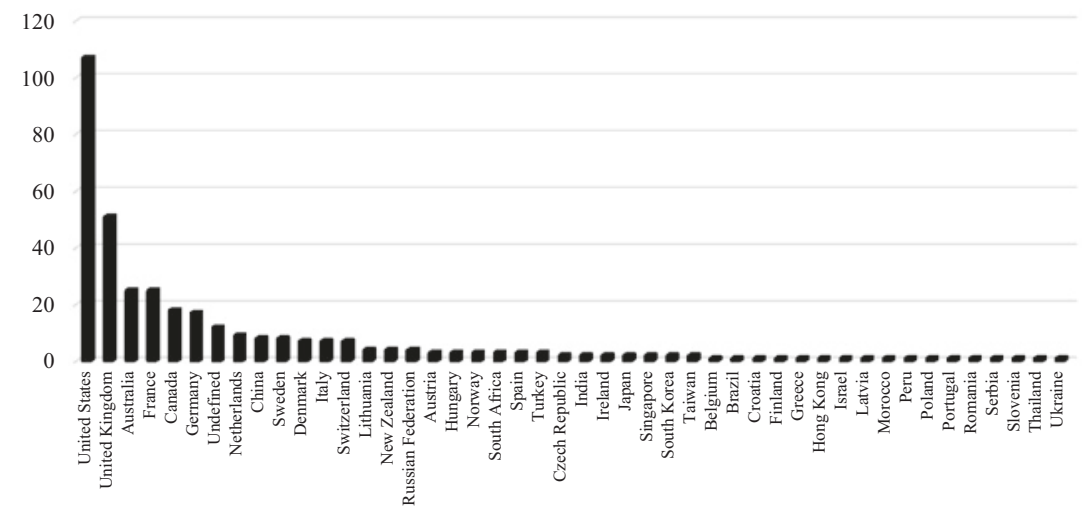

Fig. 4.2 Absolute frequency of articles by Scholars' location on the final sample 
Analysis of the research quality of HFT publications suggests that since the appearance of the seminal paper of Hendershott et al. (2011), 21 articles were published in ABS 4* Journals (Journal of Finance, Journal of Accounting Research, Journal of Accounting and Economics, Journal of Financial Economics, Quarterly Journal of Economics, Review of Economic Studies, Review of Financial Studies), 5 articles were published by ABS 4 journals and another 103 articles by ABS 3 journals (Tables 4.1 and 4.2) AT research is not only topical but is considered a priority by the major high-quality journals.

\subsection{RESUlts}

\subsubsection{Thematic Analysis}

A thematic analysis was performed to identify and classify the main themes discussed in the literature (Clarke and Braun 2013). Furthermore, a citation analysis based on the Scopus index (Dumay 2014) was used to identify articles and authors that have the most impact in HFT research (Garfield 1977). Table 4.3 presents the distribution of a subsample of 168 articles that have been classified by topic. Only the articles published on the highest rated ABS-ranked journals $4^{*}, 4,3$ and 2 (with at least 1 citation) have been included in the subsample. The table reports both frequency and sum of citations by topic. The latter table suggests four main research paths i.e.

1. effects on market quality and price discovery,

2. trading strategies,

3. impact of financial markets structure, regulation and co-location, and

4. HFT reaction to corporate disclosure.

The most cited articles discuss both about effects of HFT on market quality ( 1098 citations related to the $34.5 \%$ of articles in the sample) and the trading strategies implemented (259 citations related to 36 articles).

\subsubsection{Impact of HFT}

\subsubsection{Effects on Market Quality}

In the last years, several studies have examined the consequences of HFTs on market quality by investigating both various dimensions of 


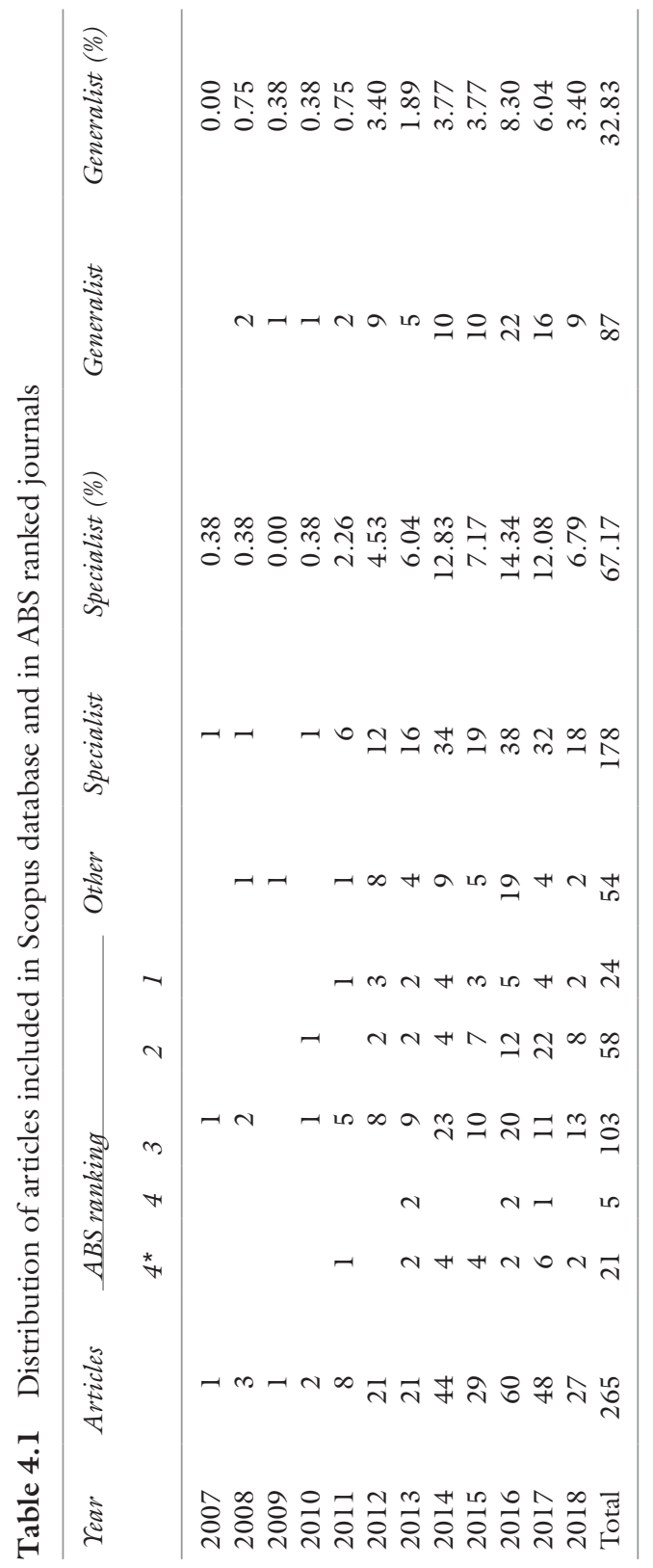


Table 4.2 Distribution of articles included in Scopus database and in the top ABS ranked journals $\left(4^{*}-4-3\right)$

\begin{tabular}{|c|c|c|c|}
\hline Journals & $N$ & $\%$ & $\begin{array}{l}A B S \\
\text { ranking }\end{array}$ \\
\hline Quantitative Finance & 19 & 7.17 & 3 \\
\hline Journal of Financial Markets & 17 & 6.42 & 3 \\
\hline Financial Review & 12 & 4.53 & 3 \\
\hline Journal of Financial Economics & 9 & 3.40 & $4^{*}$ \\
\hline Journal of Banking and Finance & 9 & 3.40 & 3 \\
\hline Journal of Futures Markets & 7 & 2.64 & 3 \\
\hline Journal of Finance & 5 & 1.89 & $4^{*}$ \\
\hline $\begin{array}{l}\text { Journal of International Financial Markets, Institutions } \\
\text { and Money }\end{array}$ & 5 & 1.89 & 3 \\
\hline Annual Review of Financial Economics & 3 & 1.13 & 3 \\
\hline European Journal of Finance & 3 & 1.13 & 3 \\
\hline International Review of Financial Analysis & 3 & 1.13 & 3 \\
\hline Journal of Accounting Research & 2 & 0.75 & $4^{*}$ \\
\hline Review of Financial Studies & 2 & 0.75 & $4^{*}$ \\
\hline Journal of Financial and Quantitative Analysis & 2 & 0.75 & 4 \\
\hline Applied Econometrics & 2 & 0.75 & 3 \\
\hline European Financial Management & 2 & 0.75 & 3 \\
\hline Finance and Stochastics & 2 & 0.75 & 3 \\
\hline Journal of Business Ethics & 2 & 0.75 & 3 \\
\hline Journal of Economic Behavior and Organization & 2 & 0.75 & 3 \\
\hline Journal of Economic Dynamics and Control & 2 & 0.75 & 3 \\
\hline Journal of Empirical Finance & 2 & 0.75 & 3 \\
\hline Journal of Financial Econometrics & 2 & 0.75 & 3 \\
\hline Mathematical Finance & 2 & 0.75 & 3 \\
\hline Review of Quantitative Finance and Accounting & 2 & 0.75 & 3 \\
\hline Journal of Accounting and Economics & 1 & 0.38 & $4^{*}$ \\
\hline Quarterly Journal of Economics & 1 & 0.38 & $4^{*}$ \\
\hline Review of Economic Studies & 1 & 0.38 & $4^{*}$ \\
\hline Business Ethics Quarterly & 1 & 0.38 & 4 \\
\hline Journal of Economic Perspectives & 1 & 0.38 & 4 \\
\hline Journal of Economic Theory & 1 & 0.38 & 4 \\
\hline Financial Analysts Journal & 1 & 0.38 & 3 \\
\hline Financial Markets, Institutions and Instruments & 1 & 0.38 & 3 \\
\hline International Journal of Finance and Economics & 1 & 0.38 & 3 \\
\hline Journal of Financial Services Research & 1 & 0.38 & 3 \\
\hline Journal of International Money and Finance & 1 & 0.38 & 3 \\
\hline Articles in $\mathrm{ABS} 4^{*}, 4,3$ ranked journals & 129 & 48.68 & - \\
\hline Articles in ABS 2,1 ranked journals and other journals & 136 & 51.32 & - \\
\hline Total articles & 265 & 100 & \\
\hline
\end{tabular}


Table 4.3 Absolute and percentage frequency of articles by topic and by Scopus citations

\begin{tabular}{lcccc}
\hline Topics & Frequency & $\%$ & Citations & $\%$ \\
\hline Market quality & 58 & 34.5 & 1098 & 91.3 \\
Trading strategies and speed & 36 & 21.4 & 259 & 21.5 \\
Financial markets structure & 14 & 8.33 & 134 & 11.1 \\
Regulation and co-location & 11 & 6.15 & 74 & 6.16 \\
Price discovery & 10 & 5.95 & 113 & 9.4 \\
Flash crash & 5 & 2.98 & 42 & 3.49 \\
Financial disclosure & 3 & 1.79 & 46 & 3.83 \\
Transaction costs & 3 & 1.79 & 26 & 2.16 \\
Dark market fragmentation & 2 & 1.19 & 11 & 0.92 \\
Investors strategies & 2 & 1.19 & 39 & 3.24 \\
Order-to-trade & 3 & 1.79 & 9 & 0.75 \\
Disposition effect & 1 & 0.6 & 6 & 0.5 \\
Hawkes processes & 1 & 0.6 & 6 & 0.5 \\
Other & 19 & 11.3 & 238 & 19.8 \\
Total & 168 & 100 & 1202 & 100 \\
\hline
\end{tabular}

price discovery, short-term volatility and stock liquidity (Hasbrouck and Saar 2013; Malinova et al. 2013; Menkveld 2013; Conrad et al. 2015). Specifically, researchers found that the introduction of HFT has been accompanied by a reduction in trading costs (Angel et al. 2015; Jones 2013) and by an improvement in price efficiency (Carrion 2013; Brogaard et al. 2014; Chaboud et al. 2014).

Examining the NYSE automated quote dissemination in 2003, the seminal paper of Hendershott et al. (2011) measures the causal effect of AT on liquidity, and demonstrates that AT activity narrows spreads, reduces both adverse selection and trade-related price discovery. Other studies highlight how HFT's market share has boomed over the number of years. Examining the role of AT in liquidity supply in 30 DAX stocks on the Deutsche Boerse, Hendershott et al. (2011) find that AT represent $52 \%$ of market order volume and $64 \%$ of nonmarketable limit order volume. Similarly, Hagströmer and Nordén (2013) report that market markets constitute the lion share of HFT trading volume (63-72\%) and limit order traffic 81-86\% of NASDAQ-OMS Stockholm Exchange. These results demonstrate that AT consume liquidity when it is cheap (narrow bid-ask spread or other proxies such as effective spread, percentage spread or higher depth) given that it is less likely to submit new orders, to cancel their orders and more likely to initiate trades. Similarly, 
Yao and Ye (2018) find that HFT liquidity supply is larger for stocks for which the spread is constrained to be large because of tick size. Jarnecic and Snape (2014) describe the HFT provision of liquidity on an ongoing basis which robust to fast versus slow and volatile markets resolving in this way the temporal liquidity imbalances.

Other studies examine HFT consequences around specific events such as earnings announcements (EPMs) (Frino et al. 2017), short sale-ban (Brogaard et al. 2017), predictable trades (Bessembinder et al. 2016) and extreme price movements (EPMs) (Brogaard et al. 2018), generally confirming the liquidity improvement.

Using the September 2008 short sale-ban, Brogaard et al. (2017) disentangle the separate impact of short selling by HFTs and non-HFTs. They suggest that non-HFTs increase liquidity (as measured by bid-ask spreads) while HFTs' short selling has the opposite effect by adversely selecting limit orders which decrease liquidity during extremely volatile short-sale ban period. Brogaard et al. (2018) investigate the activity of a common endogenous liquidity providers (ELPs), such as HFTs, around EPMs discovering that on average HFTs provide liquidity not only during normal market conditions but also around a market stress such as EPMs.

Other studies have focused on HFT strategies and their influence on market quality. For example, Hagstromer and Nordén (2013) examine the tick-size changes and find that the activity of market-making HFTs mitigates intraday price volatility (or short-term volatility for Boehmer et al. 2015), and thus can contain the deterioration of market quality.

\subsubsection{HFT's Trading Strategies and Speed}

The SEC's Concept release on Equity Market Structure recognised not only that the advent of HFTs is one of the most significant market structure developments in recent years (SEC 2010) but identified the existence of four types of short-term HFTs trading strategies-passive market making, arbitrage, structural and directional.

"Passive market making" involves the submission of non-marketable resting orders that provide liquidity to the marketplace at specified prices. Following this strategy, HFT orders are not executed immediately but rest on an order book and prices are updated frequently to reflect market conditions. In this way HFTs generate a great number of order cancellations or modifications as orders are updated and earn a spread between bids and offers. This passive strategy decreases effective spread 
as demonstrated by Menkveld (2013). Similarly, the "arbitrage strategy" does not depend on directional price movements but on price convergence seeking to keep the differences between related products or markets.

If HFTs follow "structural strategies", they attempt to find the weakness in the market structure to take advantage of the other participants. In fact, given HFT can access market data in real time, the lower latency allows them to establish prices both on the seller and buyer side. In contrast, "directional strategies" involve establishing a short position in anticipation of a price move up or down. The Concept Release (SEC 2010) requested comment on two types of directional strategies, order anticipation and momentum ignition, that "may pose particular problems for long-term investors" and "may present serious problems in today's market structure".

Regarding HFT speed, Menkveld (2016) estimates that algorithms have a response time in the order of microseconds (one microsecond is $\left.10^{-6}\right)$. Therefore, even if HFT effects on the market are known, both in terms of less adverse-selection cost, tighter bid-ask spread (higher liquidity), frequent quote updates between trades and higher price discovery between the quoted updates, and a higher trade probability (Brogaard et al. 2018), the main concerns of regulators remain whether their speed represents a barrier that limits retail investor trading activity. Moreover, regarding the open question regarding whether HFTs are better informed agents, few studies (Goettler et al. 2009; Ait-Sahalia and Saglam 2013) find a liquidity improvement when market makers become more informed about fundamental value. Agents arrive randomly and, conditional on the state of the limit-order book, they can choose to send either a limit or a market order. Other studies discussed HFT speed to cancel their outstanding limit order after news (Hoffmann 2014), an endogenous strategy that post limit orders at less aggressive prices, reducing the trade rate.

Finally, observing the price competition in a limit-order market Bongaerts et al. (2016) discover that the increase of HFT has as the final effect a general improvement of liquidity.

\subsubsection{Market Structure, Co-location and Regulation After the Flash Crash} On 6 May 2010, the US financial markets experienced the Flash Crash. Nearly one trillion US dollars' worth of equity vanished in minutes resulting from a large automated selling program being rapidly executed in the E-mini S\&P 500 stock index futures market (Kirilenko et al. 2017). 
Although HFTs were blamed for this systemic intraday event, an investigation of the FINRA Dataset shows that 6 out of 12 HFTs reduced their trading activity in the market "sometime after the crash which caused a decline in overall market liquidity. Hence, High-frequency traders did accelerate the rate of crash" (Chung et al. 2016, pp. 17-18).

The Flash Crash highlighted for the first time both the changes in trading speed and in the market's structure, a new arena where the low-frequency traders (LFTs) can only fail to defend themselves from predatory HFTs strategies (Goldstein et al. 2014). It remains still unclear if it is the presence of a weak financial market structure that generates negative events (like the Flash Crash) or whether the latter can be caused by HFT activity. In this respect, Conrad et al. (2015, p. 290) discuss "[...] while dislocations are harmful to market integrity, it is important to recognize that some discontinuities have always occurred in markets (even before the age of electronic trading), just as flickering quotes have existed well before the advent of high-frequency quotation...if liquidity provision is not mandated by law, liquidity providers can always exit without notice, exposing marketable orders to price risk".

Some Scholars argue that exchanges have modified their market structure (Menkveld and Yueshen 2017) to attract more high-frequency traders by, among other things, permitting "algorithmic traders to co-locate their servers in the market's data centre" (Hendershott et al. 2011). This co-location reduces latency and permits HFT to more quickly adjust their quotes as market conditions change and to decrease bid-ask spreads and increase market depth in the period following the introduction of these new facilities (Frino et al. 2014). Using colocation services as a proxy for AT and HFT, Aitken et al. (2014) examine the impact of changes in AT and HFT on trade size across 24 stock exchanges around the world. Mixed results on AT and HFT effects on the average trade size (used to identify AT and HFT start dates) were found. The study also demonstrated, for the first time, that even if the introduction of co-location facilities leads to the presence of HFT, the "colocation dates" do not properly measure effective AT and HFT (Aitken et al. 2014) that may enter into the market a few months before or after the co-location launch (Frino et al. 2017).

While on one hand the main stock exchanges seek to attract a larger number of HFT, both reducing the low latency and introducing new trading platforms, on the other hand many regulators around the world are trying to limit the massive volume of messages (orders), as submissions and cancellations, made by high-frequency traders. More recently, many regulators have attempted to discourage the HFT activity by 
introducing a specific tax to limit high volumes of messages and cancellations despite the lack of agreement on the negative effects of this legislation on capital market quality. On 1 August 2012, the French government introduced a financial transaction tax applicable on cancelled orders made by high-frequency traders where all orders cancelled or modified within half-second time span are taxed. The tax of $0.01 \%$ is applied on modified or cancelled orders of French HFT when OTR is greater than five (Chung et al. 2016), even if in this case it did not have any negative on market quality, both in term of trading volume, volatility, spreads and depth (Colliard and Hoffmann 2017).

Similarly, on I March 2013 Italy introduced the iFTT (Italian Financial Transaction Tax) imposing tax on (1) the transfers of the ownership of shares and other participating financial instruments, (2) transactions in derivative financial instruments and other transferable securities, and (3) HFT (MEF 2013). The initiative was launched by the Italian Securities and Exchange Commission (CONSOB) which introduced the iFTT with the specific goal of containing the rapid placement and cancellation of orders. In fact, a recent study suggests that orders' cancellations "can generate a misleading representation of the actual depth of the order book, creating favourable conditions for market manipulation" (Friederich and Payne 2015, p. 215). The iTFF was the first order-to-trade ratio tax (OTR) to attempt to reduce the perceived harmful behaviours of $\mathrm{HFT}^{2}$ but the new regulation resulted in lower average Italian OTRs (Caivano et al. 2012) and a negative effect on market liquidity (Friederich and Payne 2015). ${ }^{3}$ Despite these findings, the taxation of HFT is set to continue. Norway, Germany and Canada have introduced OTR to limit HFT activity (Malinova et al. 2013; Haferkorn and Zimmermann 2014).

\subsubsection{HFT Reaction to Corporate Disclosure}

Recently Allee et al. (2018) demonstrated the effect of the "scriptability" of firm disclosures on capital markets. Scriptability represents the relative

\footnotetext{
${ }^{2}$ The tax became effective in Borsa Italiana on April 2012 and it intended to charge a fee to HFT with OTF higher than 100:1, 500:1 or 1000:1 (see Grant and Rachel 2012).

${ }^{3}$ Opposite results have been found by Capelle-Blancard (2016).
} 
ease with "which a computer program or a computer programmer can transform the large amounts of unstructured data contained in various firm disclosures into usable information (Bloomfield 2002)". The general assumption here is that "more scriptable" filings allow HFT (and other sophisticated investors) gain a short-term information advantage to react and trade quickly and increase the information asymmetry immediately following disclosures; bid-ask spreads increase by $20-25 \%$ in the $30-60$ seconds following Form 4 filings (Rogers et al. 2017). Similar results have been found by Frino et al. (2017) that demonstrate that spreads increase at the time of the event and decrease in the following minutes.

\subsection{Conclusion and Future Research Directions}

The advent of HFT and the introduction of co-location services and other facilities irredeemably changed market structures around the world. Consequently, transaction costs have decreased sharply-by over $50 \%$ for both retail and institutional investors (Menkveld 2016). Several studies discuss the consequences of HFT activity on market quality and find a rise in both trading volume and in the number of orders (trades), as well as large increases in the number of submissions (messages) and cancellations. However, the lack of identification codes (in the main financial dataset available) does not allow the disentanglement of trading activity by different type of investors (institutional vs. retail investors). As a result, both the number of orders and the number of submissions or cancellations (messages) are commonly used to build proxies that allow the detection of HFT activity thereby allowing scholars to detect the consequences of HFT activity in the main financial markets.

Studies of the impact of HFT suggest that information asymmetry between buyers and sellers is reduced over the time and, even if very often HFT are accused of arbitrage, many empirical studies demonstrate a general improvement in market liquidity (as measured by reduction of spreads or increases in depth) and a general reduction of the intraday price volatility. These results ultimately suggest that any regulatory action introduced to curtail this activity may have serious negative implications for liquidity and market participants (Frino et al. 2017), as demonstrated recently both in France and in Italy (Friederich and Payne 2015).

The large volume of papers published on the topic of AT and HFT indicate a clear academic interest in the potential contributions and 
limitations of HFT activity. However, many open questions remain unanswered:

- It is not clear if the systemic risk is embedded in electronic trading or really caused by HFT.

- The HFT strategies are still partially undiscovered given that the majority of studies use proxies to detect their activity rather than identifiers. Consequently, the latter information might provide a clear evidence of the real impact of the different trading strategies on market quality.

- Only a few studies highlight the effects of HFT activity around specific events like earnings announcements (Frino et al. 2017), news (Scholtus et al. 2014) or macro-news announcements (Bernile et al. 2016) but how do HFTs react around other specific events like mergers and acquisitions or social media releases? What is the effect of their activity on market quality in such cases?

- How do HFTs react to narrative accounting disclosure? Given that the corporate disclosure is moving towards "machine readable" reports, how can firms anticipate HFT trading strategies at the time of disclosure?

Firms and investors should take into consideration that with the advent of HFTs the speed of dissemination of information (earnings, good or bad news, buy or sell quotes and trades) has changed, capital markets have evolved, and complex algorithms may soon become obsolescent.

In 2009 and 2010, HFT techniques were considered a goldmine for sophisticated investors that know how to deploy them against human competitors, however 'dumb' competitors got wise and began to employ similar strategies to defend their wealth stores (Financial Times 2017). According to Tabb Group, the US market makers reported \$1.1 billion in revenue in 2016, compared with $\$ 7.2$ billion in 2009 . This phenomenon demonstrates a slowdown in the world of HFT with lower profitability. As HFT speed no longer accrues a significant competitive advantage, sophisticated investors are now trying to capture a competitive advantage in predicting markets through quantitative models and artificial intelligence (AI) throwing up new challenges and opportunities for investors, policymakers and scholars alike. 


\section{REFERENCES}

Aitken, M., Cumming, D., \& Zhan, F. (2014). Trade size, high-frequency trading, and colocation around the world. The European Journal of Finance, 1-21. https://www.tandfonline.com/doi/abs/10.1080/1351847X.2014.917119.

Ait-Sahalia, Y., \& Saglam, M. (2013). High frequency traders: Taking advantage of speed (No. w19531). National Bureau of Economic Research.

Aldridge, I., \& Krawciw, S. (2017). Real-time risk: What investors should know about FinTech, high-frequency trading, and flash crashes. Hoboken, NJ: Wiley.

Allee, K. D., DeAngelis, M. D., \& Moon, J. R., Jr. (2018). Disclosure "Scriptability". Journal of Accounting Research, 56(2), 363-430.

Angel, J. J., Harris, L. E., \& Spatt, C. S. (2015). Equity trading in the 21 st century: An update. The Quarterly Journal of Finance, 5(1). https://www.worldscientific.com/doi/abs/10.1142/S2010139215500020.

Baron, M., Brogaard, J., Hagströmer, B., \& Kirilenko, A. A. (2017). Risk and return in high-frequency trading. Journal of Financial and Quantitative Analysis (JFQA), Forthcoming. Available at SSRN: https://ssrn.com/ abstract $=2433118$.

Bernile, G., Hu, J., \& Tang, Y. (2016). Can information be locked up? Informed trading ahead of macro-news announcements. Journal of Financial Economics, 121(3), 496-520.

Bessembinder, H., Carrion, A., Tuttle, L., \& Venkataraman, K. (2016). Liquidity, resiliency and market quality around predictable trades: Theory and evidence. Journal of Financial Economics, 121(1), 142-166.

Bloomfield, R. J. (2002). The "incomplete revelation hypothesis" and financial reporting. Accounting Horizons, 16(3), 233-243.

Boehmer, E., Li, D., \& Saar, G. (2015). Correlated high-frequency trading. Manuscript, Cornell University, Ithaca, NY.

Boehmer, E., Fong, K. Y. L., \& Wu, J. (2018). Algorithmic trading and market quality: International evidence (AFA 2013 San Diego Meetings Paper). Available at SSRN: https://ssrn.com/abstract=2022034.

Bongaerts, D., Kong, L., \& Van Achter, M. (2016). Trading speed competition: Can the arms race go too far? Available at SSRN: https://ssrn.com/ abstract $=2779904$.

Bouveret, A., Guillaumie, C., Roqueiro, C. A., Winkler, C., \& Nauhaus, S. (2014). High-frequency trading activity in EU equity markets. ESMA Report on Trends, Risks and Vulnerabilities, 1, 41-47.

Brogaard, J., Hendershott, T., Hunt, S., \& Ysusi, C. (2014). High-frequency trading and the execution costs of institutional investors. Financial Review, $49(2), 345-369$.

Brogaard, J., Hendershott, T., \& Riordan, R. (2017). High frequency trading and the 2008 short-sale ban. Journal of Financial Economics, 124(1), 22-42. 
Brogaard, J., Carrion, A., Moyaert, T., Riordan, R., Shkilko, A., \& Sokolov, K. (2018). High frequency trading and extreme price movements. Journal of Financial Economics, 128(2), 253-265.

Brunnermeier, M., \& Pedersen, L. H. (2005). Predatory trading. The Journal of Finance, 60(4), 1825-1863.

Caivano, V., Ciccarelli, S., Stefano, G. D., Fratini, M., Gasparri, G., Giliberti, M., et al. (2012, December). High frequency trading: Definition, effects, policy issues. CONSOB (Commissione Nazionale per le Societá e la Borsa) (Discussion Paper No. 5). pp. 1-60.

Capelle-Blancard, G., \& Havrylchyk, O. (2016). The impact of the french securities transaction tax on market liquidity and volatility. Available on SSRN: https://papers.ssrn.com/sol3/papers.cfm?abstract_id=2378347.

Carrion, A. (2013). Very fast money: High-frequency trading on the NASDAQ. Journal of Financial Markets, 16(4), 680-711.

Chaboud, A. P., Chiquoine, B., Hjalmarsson, E., \& Vega, C. (2014). Rise of the machines: Algorithmic trading in the foreign exchange market. The Journal of Finance, 69(5), 2045-2084.

Chung, K. H., \& Lee, Albert J. (2016). High-frequency trading: Review of the literature and regulatory initiatives around the world. Asia-Pacific Journal of Financial Studies, 45(1), 7-33.

Clarke, V., \& Braun, V. (2013). Teaching thematic analysis: Overcoming challenges and developing strategies for effective learning. The Psychologist, 26(2), 120-123.

Clark-Joseph, A. (2013). Exploratory trading. Unpublished job market paper. Harvard University, Cambridge, MA.

Colliard, J. E., \& Hoffmann, P. (2017). Financial transaction taxes, market composition, and liquidity. The Journal of Finance, 72(6), 2685-2716.

Conrad, J., Wahal, S., \& Xiang, J. (2015). High-frequency quoting, trading, and the efficiency of prices. Journal of Financial Economics, 116(2), 271-291.

Dumay, J. (2014). 15 years of the journal of intellectual capital and counting: A manifesto for transformational IC research. Journal of Intellectual Capital, 15(1), 2-37.

European Union, MIFID II - Directive 2014/65/EU of the European Parliament and of the Council of 15 May 2014 on markets in financial instruments and amending the Insurance Mediation Directive and AIFMD. Article, $4(1)(39)$.

Friederich, S., \& Payne, R. (2015). Order-to-trade ratios and market quality. Journal of Banking \& Finance, 50, 214-223.

Frino, A., Mollica, V., \& Webb, R. I. (2014). The impact of co-location of securities exchanges' and traders' computer servers on market liquidity. Journal of Futures Markets, 34(1), 20-33.

Frino, A., Mollica, V., Monaco, E., \& Palumbo, R. (2017). The effect of algorithmic trading on market liquidity: Evidence around earnings announcements on Borsa Italiana. Pacific-Basin Finance Journal, 45, 82-90. 
Garfield, E. (1977). Introducing citation classics-human side of scientific reports. Current Comments, 1, 5-7.

Goettler, R. L., Parlour, C. A., \& Rajan, U. (2009). Informed traders and limit order markets. Journal of Financial Economics, 93(1), 67-87.

Goldstein, M. A., Kumar, P., \& Graves, F. C. (2014). Computerized and high-frequency trading. Financial Review, 49(2), 177-202.

Grant, J., \& Rachel S. (2012). Italy to limit high-frequency orders Financial Times. Available at: https://www.ft.com/content/1bbcc370-5bb5-11ela447-00144feabdc0. Last accessed 16 August 2018.

Haferkorn, M., \& Zimmermann, K. (2014). The German high-frequency trading act: Implications for market quality. Available at SSRN: https://ssrn.com/ abstract $=2514334$.

Hagströmer, B., \& Nordén, L. (2013). The diversity of high-frequency traders. Journal of Financial Markets, 16(4), 741-770.

Hasbrouck, J., \& Saar, G. (2013). Low-latency trading. Journal of Financial Markets, 16(4), 646-679.

Hendershott, T., Jones, C. M., \& Menkveld, A. J. (2011). Does algorithmic trading improve liquidity? The Journal of Finance, $66(1), 1-33$.

Hoffmann, P. (2014). A dynamic limit order market with fast and slow traders. Journal of Financial Economics, 113, 156-169.

Jarnecic, E., \& Snape, M. (2014). The provision of liquidity by high-frequency participants. Financial Review, 49(2), 371-394.

Jones, C. M. (2013). What do we know about high-frequency trading? (Columbia Business School Research Paper No. 13-11). Available at SSRN: https://ssrn. com $/$ abstract $=2236201$.

Kaminska, I. (2017, March 28). HFT as an insight into where fintech is going, Financial Times. Available at FT: https://ftalphaville. ft.com/2017/03/28/2186482/hft-as-an-insight-into-where-fintech-is-going/.

Kirilenko, A., Kyle, A., Mehrdad, S., \& Tugkan, T. (2017). The flash crash: The impact of high frequency trading on an electronic market. The Journal of Finance, 72(3), 967-998.

Malinova, K., Park, A., \& Riordan, R. (2013). Do retail traders suffer from high frequency traders. Available at SSRN: 2183806.

Massaro, M., Dumay, J., \& Guthrie, J. (2016). On the shoulders of giants: Undertaking a structured literature review in accounting. Accounting, Auditing \& Accountability Journal, 29(5), 767-801.

Menkveld, A. J. (2013). High frequency trading and the new market makers. Journal of Financial Markets, 16(4), 712-740.

Menkveld, A. J. (2016). The economics of high-frequency trading: Taking stock. Annual Review of Financial Economics, 8, 1-24.

Menkveld, A. J. \& Yueshen, B. Z. (2017). The flash crash: A cautionary tale about highly fragmented markets. Management Science, Forthcoming. Available at SSRN: https://ssrn.com/abstract $=2243520$. 
Ministry of Economy and Finance (MEF). (2013). Explanatory memorandum. Available at: http://www.mef.gov.it/primo-piano/documenti/Relazione_ Illustrativa_English_version_6_2_2013.pdf. Last accessed 16 August 2018.

Prix, J., Loistl, O., \& Huetl, M. (2007). Algorithmic trading patterns in Xetra orders. The European Journal of Finance, 13(8), 717-739.

Rogers, J. L., Skinner, D. J., \& Zechman, S. L. (2017). Run EDGAR run: SEC dissemination in a high-frequency world. Journal of Accounting Research, $55(2), 459-505$.

Scholtus, M., van Dijk, D., \& Frijns, B. (2014). Speed, algorithmic trading, and market quality around macroeconomic news announcements. Journal of Banking \& Finance, 38, 89-105.

Securities, ASIC-Australian, and Investments Commission. (2010). Report 215: Australian equity market structure. Available at: https://download.asic.gov. $\mathrm{au} / \mathrm{media} / 1343084 / \mathrm{rep}-215$.pdf. Last accessed 16 August 2018.

U.S. Commodity Futures Trading Commission and the U.S. Securities and Exchange Commission (CFTC and SEC). (2010). Findings regarding the market events of May 6, 2010. Available at: https://www.sec.gov/news/studies $/ 2010 /$ marketevents-report.pdf. Last accessed 16 August 2018.

U.S. Securities and Exchange Commission (SEC). (2010). Concept Release on Equity Market Structure 34-61358. Available at: https://www.sec.gov/rules/ concept/2010/34-61358fr.pdf. Last accessed 18 August 2018.

Yao, C., \& Ye, M. (2018). Why trading speed matters: A tale of queue rationing under price controls. The Review of Financial Studies, 31(6), 2157-2183.

Open Access This chapter is licensed under the terms of the Creative Commons Attribution-NonCommercial-NoDerivatives 4.0 International License (http://creativecommons.org/licenses/by-nc-nd/4.0/), which permits any noncommercial use, sharing, distribution and reproduction in any medium or format, as long as you give appropriate credit to the original author(s) and the source, provide a link to the Creative Commons license and indicate if you modified the licensed material. You do not have permission under this license to share adapted material derived from this chapter or parts of it.

The images or other third party material in this chapter are included in the chapter's Creative Commons license, unless indicated otherwise in a credit line to the material. If material is not included in the chapter's Creative Commons license and your intended use is not permitted by statutory regulation or exceeds the permitted use, you will need to obtain permission directly from the copyright holder.

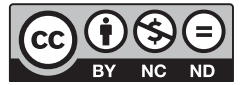

